\title{
Association of ABO Blood Types and Clinicopathological Features of Prostate Cancer
}

\author{
Fang-Ming Wang, ${ }^{1}$ Yan Zhang, ${ }^{2}$ Gui-Ming Zhang, ${ }^{1}$ Ya-Nan Liu, ${ }^{1}$ Li-Jiang Sun, ${ }^{1}$ and \\ Yong Liu ${ }^{1}$ \\ ${ }^{1}$ Department of Urology, The Affiliated Hospital of Qingdao University, Qingdao, Shandong 266003, China \\ ${ }^{2}$ Division of Dyslipidemia, State Key Laboratory of Cardiovascular Disease, Fu Wai Hospital, National Center for Cardiovascular \\ Diseases, Chinese Academy of Medical Sciences, Peking Union Medical College, Bei Li Shi Road 167, Beijing 100037, China
}

Correspondence should be addressed to Fang-Ming Wang; qingyifangming@163.com, Li-Jiang Sun; slijiang999@126.com, and Yong Liu; qyfyliuy@163.com

Received 23 July 2017; Revised 19 August 2017; Accepted 6 September 2017; Published 9 October 2017

Academic Editor: Michele Malaguarnera

Copyright (c) 2017 Fang-Ming Wang et al. This is an open access article distributed under the Creative Commons Attribution License, which permits unrestricted use, distribution, and reproduction in any medium, provided the original work is properly cited.

Purpose. To investigate the association between $\mathrm{ABO}$ blood types and clinicopathological characteristics in patients with prostate cancer (PC). Methods. A total of 237 pathologically diagnosed PC patients were enrolled. All patients were classified as low-middle or high-risk group. The correlation of $\mathrm{ABO}$ blood types with high-risk PC was determined by univariate and multivariate regression analysis. Results. Data indicated 144 (85.7\%) patients were stratified as high risk in the non-O group, while $50(72.5 \%)$ patients in the $\mathrm{O}$ group $(p=0.025)$. However, there was no significant difference regarding PSA, Gleason score, stage, or metastasis between $\mathrm{O}$ and non-O group $(p>0.05)$. Univariate logistic regression analyses revealed PSA, Gleason score, and blood type non-O were all correlated with high-risk PC $(\mathrm{OR}=1.139, p<0.001 ; \mathrm{OR}=9.465, p<0.001 ; \mathrm{OR}=2.280, p=0.018$, resp. $)$. In the stepwise multivariate regression analysis, the association between blood type non-O and high-risk $\mathrm{PC}$ remained significant $(\mathrm{OR}=33.066$, 95\% CI 2.391-457.323, and $p=0.009$ ) after adjusting for confounding factors as well as PSA and Gleason score. Conclusion. The present study firstly demonstrated that non-O blood type was at higher risk of aggressive PC compared with O type, suggesting that PC patients with non-O blood type should receive more attention in clinical practice.

\section{Introduction}

Prostate cancer (PC) is the most common cancer among males in the Western world, with more than 1.11 million new cases diagnosed in 2012 and 307,000 deaths [1, 2]. PC is also now becoming an emerging health priority in East Asia due to exposure to westernized diet and lifestyle [3]. It is expected that the incidence will substantially increase in the coming decades due to the aging population, which makes it a huge health care problem. It is crucial and desirable to evaluate and predict the risk of PC appropriately.

Although preoperative prostate-specific antigen (PSA) levels, Gleason score in the biopsy specimen, and clinical stages are well-established predictors of PC, identification of additional factors which can help us to better estimate and evaluate the severity of PC is expected to be useful for patient counseling. The ABO blood group is determined by the presence of A or B blood group antigens on the surface of red blood cells, which consist of proteins and carbohydrates attached to lipids or proteins. ABO blood group antigens are also found in a variety of epithelial cells; therefore, the clinical significance of the $\mathrm{ABO}$ blood group system extends beyond transfusion medicine [4]. The ABO blood group has been associated with a number of nonneoplastic diseases [5-10]. Furthermore, associations have also been made between the ABO blood group and certain malignancies including cancers of the pancreas $[11,12]$, ovary [13], kidney [14], and skin [15]. For example, it has been reported that individuals with non-O blood groups have an elevated risk of developing gastric and pancreatic cancers [4].

To date, few studies have investigated potential associations between $\mathrm{ABO}$ blood groups and the risk of PC. Lack 
of association between blood type and PC risk has been reported [12]. However, to the best of our knowledge, whether $\mathrm{ABO}$ blood types associated with the clinicopathological characteristics of pathologically confirmed PC has not been reported. Accordingly, in the present study, we sought to determine the association between $\mathrm{ABO}$ blood groups and clinicopathological features including the risk of PC in 237 pathologically diagnosed patients.

\section{Methods}

2.1. Study Design and Population. The study complied with the Declaration of Helsinki and was approved by our Institute Ethical Committee. All subject names, initials, or hospital numbers were not used in the text, table, or illustrative materials of this study.

The study was conducted in patients with primary diagnosed, pathologically confirmed sporadic PC, between January 2011 and August 2016 at the Department of Urology at the Affiliated Hospital of Qingdao University. The exclusion criteria of the study were the presence of medical history of other malignancies, incomplete information of pathological characteristics, or ABO blood type records. All data on age, body mass index (BMI), history of hypertension or diabetes, serum PSA, biopsy cancer grade (Gleason score), tumor clinical stage at diagnosis, treatment protocols, and ABO blood type status were obtained from electronic records and medical charts. All the pathological data analyzed in this study were identified from the transrectal ultrasound-guided prostate biopsy specimens. All specimens were processed according to standard pathological procedures. Tumor stage was assessed according to the American Joint Committee on Cancer (AJCC) TNM classification of malignant tumors 2002. Gleason score was assessed according to the ISUP classification of 2005 [16].

2.2. Exposure Definition. Risk factor definitions were as follows. (1) BMI was defined as the first reported weight (in kilograms) divided by height in square meters, and $\mathrm{BMI} \geq 25 \mathrm{~kg} / \mathrm{m}^{2}$ was considered as overweight; (2) the threshold of hypertension was set at 140 and $90 \mathrm{mmHg}$ for systolic and diastolic blood pressure, respectively, on three consecutive occasions; and (3) diabetes was based on either one of the following criteria: fasting serum glucose level $\geq 7.0 \mathrm{mmol} / \mathrm{L}$, normal fasting serum glucose level owing to usage of antidiabetic medication, or self-report of a physician's diagnosis of diabetes.

2.3. Statistical Analyses. Quantitative variables were expressed as mean \pm standard deviation (SD) and were analyzed by the Student's $t$-tests or one way ANOVA as appropriate. The qualitative variables were expressed as numbers and percentages and were analyzed by chi-squared statistic tests. Correlations between variables with high-risk PC were examined by univariate logistic regression analysis. Stepwise multivariate regression analysis was used to determine the independent factors of high-risk PC. A $P$ value of less than 0.05 was considered statistically significant. Statistical studies were carried out with the SPSS program (version 19.0, SPSS, Chicago, Illinois, USA).

\section{Results}

3.1. Baseline Characteristics. The current study consisted of 237 eligible pathologically confirmed PC patients (male, with a mean age of $70.7 \pm 7.9$ years). The mean Gleason score was $8.1 \pm 1.3$. The clinical stage was as follow: T1 (12 cases), T2a (31 cases), T2b (50 cases), T2c (34 cases), T3 (77 cases), and T4 (33 cases). The prevalence of the various blood groups in this study was as follows: O, 29.1\% $(n=69)$; A, $27.8 \%(n=66) ; \mathrm{B}, 33.3 \%(n=79)$; and $\mathrm{AB}, 9.7 \%(n=23)$. The distribution of $\mathrm{ABO}$ blood groups was generally similar to that found in the general population of Han Chinese [17]. The baseline demographic, clinical characteristics, and laboratory findings of the enrolled subjects were summarized in Table 1.

All PC subjects were divided into two groups: lowmiddle risk group $(n=43)$ and high-risk group $(n=194)$ according to PSA, Gleason score, and clinical stage. Lowmiddle risk is defined as follows: PSA $\leq 20 \mathrm{ng} / \mathrm{ml}$, Gleason Score $\leq 7$, and clinical stage $\leq \mathrm{T} 2 \mathrm{~b}$; high risk was based on either one of the following criteria: PSA $>20 \mathrm{ng} / \mathrm{ml}$, Gleason Score $\geq 8$, or clinical stage $\geq \mathrm{T} 2 \mathrm{c}$.

Although there was no significant association between different risk groups and the ABO blood types $(p=0.086)$, the trend was evident that patients with $\mathrm{O}$ blood type tended not to have high risk (high-risk percentage: $\mathrm{O}$ versus $\mathrm{A}$ versus $B$ versus $A B$ : $72.5 \%$ versus $86.4 \%$ versus $83.5 \%$ versus $91.3 \%$ ). Then, we further evaluated the relation of $\mathrm{O}$ and non-O subgroups to the $\mathrm{PC}$ risks and finally found that blood type $\mathrm{O}$ patients had a significantly lower risk of aggressive prostate cancer compared to type non-O patients (high-risk percentage: $\mathrm{O}$ versus non-O: $72.5 \%$ versus $85.7 \%, p=0.025$ ) (Table 1).

To evaluate the clinicopathological characteristics according to ABO blood types, as shown in Table 2, we observed that $144(85.7 \%)$ patients were stratified as high risk in the non-O group, while $50(72.5 \%)$ patients were stratified as high risk in the $\mathrm{O}$ group $(p=0.025)$. However, there was no significant difference between non-O and $\mathrm{O}$ group, regarding PSA, Gleason score, clinical stage, lymph node involvement, or bone metastasis $(p=0.999,0.234$; $p=0.434 ; p=0.232 ; p=0.542$; and $p=0.558$, resp.).

3.2. Correlations of ABO Blood Types and Other Clinical Variables with High-Risk PC. To evaluate the correlations of $\mathrm{ABO}$ blood types and other clinical variables with highrisk $\mathrm{PC}$, univariate logistic regression analysis was performed in the current study. As shown in Table 3, parameters including PSA, Gleason score, and blood type $\mathrm{O}$ or non-O found to be statistically significant in univariate analyses were entered into multivariate logistic regression analysis. The data indicated that PSA, Gleason score, blood type $\mathrm{O}$, and non-O were independently correlated with the presence of high-risk prostate cancer in multivariate logistic regression analysis. In particular, non-O blood type was proved to be an independent predictor for the presence of high-risk PC after adjusting for the known confounders $(\mathrm{OR}=2.28,95 \% \mathrm{CI}$ $1.152-4.512$, and $p=0.018$ ) (Table 4). Nevertheless, we did not observe statistically significant relationship between 
TABLE 1: Baseline characteristics of the study population according to the risk of PC.

\begin{tabular}{|c|c|c|c|c|}
\hline Variables & All subjects $(n=237)$ & Low-middle risk $(n=43)$ & High risk $(n=194)$ & $P$ value \\
\hline \multicolumn{5}{|l|}{ Demographic Characteristics } \\
\hline Age (years) & $70.7 \pm 7.9$ & $70.1 \pm 6.6$ & $70.8 \pm 8.2$ & 0.61 \\
\hline $\operatorname{BMI}(n(\%))$ & & & & 0.231 \\
\hline$<25$ & $138(58.2)$ & $29(67.4)$ & $109(56.2)$ & \\
\hline$\geq 25$ & $99(41.8)$ & $14(32.6)$ & $85(43.8)$ & \\
\hline Hypertension $(n(\%))$ & $85(35.9)$ & $13(30.2)$ & $72(37.1)$ & 0.483 \\
\hline Diabetes mellitus $(n(\%))$ & $37(15.6)$ & $7(16.3)$ & $30(15.5)$ & 0.894 \\
\hline Coronary artery disease $(n(\%))$ & $38(16.0)$ & $5(11.6)$ & $33(17.0)$ & 0.494 \\
\hline \multicolumn{5}{|l|}{ Clinicopathological characteristics } \\
\hline \multicolumn{5}{|l|}{ PSA $(n g / m l)$} \\
\hline $\mathrm{PSA} \leq 100(\mathrm{ng} / \mathrm{ml})$ & $30.4 \pm 26.3$ & $10.4 \pm 4.9$ & $38.6 \pm 27.1$ & $<0.001$ \\
\hline PSA > $100(n(\%))$ & $87(36.7)$ & $0(0)$ & $87(45.5)$ & $<0.001$ \\
\hline Gleason score & $8.1 \pm 1.3$ & $6.4 \pm 0.5$ & $8.5 \pm 1.1$ & $<0.001$ \\
\hline Stage & & & & $<0.001$ \\
\hline $\mathrm{T} 1$ & $12(5.1)$ & $10(23.3)$ & $2(1.0)$ & \\
\hline $\mathrm{T} 2 \mathrm{a}$ & $31(13.1)$ & $15(34.9)$ & $16(8.2)$ & \\
\hline $\mathrm{T} 2 \mathrm{~b}$ & $50(21.1)$ & $18(41.9)$ & $32(16.5)$ & \\
\hline $\mathrm{T} 2 \mathrm{c}$ & $34(14.3)$ & $0(0)$ & $34(17.5)$ & \\
\hline $\mathrm{T} 3$ & $77(32.5)$ & $0(0)$ & $77(39.7)$ & \\
\hline $\mathrm{T} 4$ & $33(13.9)$ & $0(0)$ & $33(17.0)$ & \\
\hline$N$ & & & & $<0.001$ \\
\hline N0 & $160(67.5)$ & $43(100)$ & $117(60.3)$ & \\
\hline N1 & $77(32.5)$ & $0(0)$ & $77(39.7)$ & \\
\hline M & & & & $<0.001$ \\
\hline M0 & $147(62.0)$ & $43(100)$ & $104(53.6)$ & \\
\hline M1 & $90(38)$ & $0(0)$ & $90(46.4)$ & \\
\hline ABO type, $n(\%)$ & & & & 0.086 \\
\hline $\mathrm{O}$ & $69(29.1)$ & $19(27.5)$ & $50(72.5)$ & \\
\hline A & $66(27.8)$ & $9(13.6)$ & $57(86.4)$ & \\
\hline $\mathrm{B}$ & $79(33.3)$ & $13(16.5)$ & $66(83.5)$ & \\
\hline $\mathrm{AB}$ & $23(9.7)$ & $2(8.7)$ & $21(91.3)$ & \\
\hline O/non-O group, $n(\%)$ & & & & 0.025 \\
\hline $\mathrm{O}$ & $69(29.1)$ & $19(27.5)$ & $50(72.5)$ & \\
\hline non-O & $168(70.9)$ & $24(14.3)$ & $144(85.7)$ & \\
\hline \multicolumn{5}{|l|}{ Surgery, $n(\%)$} \\
\hline Radical prostatectomy & $47(19.8)$ & $19(44.2)$ & $28(14.4)$ & $<0.001$ \\
\hline Bilateral orchiectomy & $56(23.6)$ & $0(0)$ & $56(28.9)$ & $<0.001$ \\
\hline
\end{tabular}

Data are expressed as $n(\%)$ or mean $\pm \mathrm{SD}$. PC = prostate cancer; $\mathrm{BMI}=$ body mass index; PSA = prostate-specific antigen.

high-risk PC and age, BMI, hypertension, diabetes mellitus, coronary artery disease, or other blood subgroups (Table 3).

\section{Discussion}

The present study evaluated the association of ABO blood types and clinicopathological features including the risk of PC. To our knowledge, this is the first study to demonstrate that patients with $\mathrm{O}$ blood type tended to have lower risk and to be less aggressive compared with non-O blood types. This association was independent of PC risk factors, since it remained significant after adjusting for other confounders. Therefore, in addition to PSA, clinical stage, and Gleason score, the current study might provide novel information with regard to the assessment of PC risk from the clinical perspectives.

ABO antigens are highly expressed not only in red blood cells but also in human tissues and most epithelial and endothelial cells $[18,19]$. Red blood cell antigens have various functions, such as membrane structural integrity, transportation of molecules through membranes, and adhesion [20]. Since ABO blood types were found to be associated with 
TABLE 2: Pathological features of the study population stratified by ABO blood type.

\begin{tabular}{|c|c|c|c|c|c|c|c|}
\hline \multirow{2}{*}{ Variables } & \multicolumn{4}{|c|}{ ABO blood types } & \multirow{2}{*}{ non-O $(n=168)$} & \multirow{2}{*}{$P$ value $^{\mathrm{a}}$} & \multirow{2}{*}{$P$ value ${ }^{\mathrm{b}}$} \\
\hline & $\mathrm{O}(n=69)$ & $\mathrm{A}(n=66)$ & $\mathrm{B}(n=79)$ & $\mathrm{AB}(n=23)$ & & & \\
\hline \multicolumn{8}{|l|}{ PSA } \\
\hline PSA $\leq 100(\mathrm{ng} / \mathrm{ml})$ & $30.4 \pm 27.5$ & $28.0 \pm 25.4$ & $31.0 \pm 24.5$ & $34.8 \pm 31.8$ & $30.4 \pm 25.9$ & 0.861 & 0.999 \\
\hline PSA $>100(n(\%))$ & $21(30.9)$ & $27(40.9)$ & $31(40.3)$ & $8(34.8)$ & $66(39.8)$ & 0.598 & 0.234 \\
\hline Gleason score & $8.03 \pm 1.4$ & $8.29 \pm 1.2$ & $8.15 \pm 1.3$ & $8.00 \pm 1.2$ & $8.18 \pm 1.2$ & 0.099 & 0.434 \\
\hline Stage & & & & & & 0.350 & 0.232 \\
\hline $\mathrm{T} 1$ & $3(4.3)$ & $1(1.5)$ & $7(8.9)$ & $1(4.3)$ & $9(5.4)$ & & \\
\hline $\mathrm{T} 2 \mathrm{a}$ & $17(24.6)$ & $6(9.1)$ & $5(6.3)$ & $3(13.0)$ & $14(8.3)$ & & \\
\hline $\mathrm{T} 2 \mathrm{~b}$ & $14(20.3)$ & $15(22.7)$ & $17(21.5)$ & $4(17.4)$ & $36(21.4)$ & & \\
\hline $\mathrm{T} 2 \mathrm{c}$ & $8(11.6)$ & $9(13.6)$ & $12(15.2)$ & $5(21.7)$ & $26(15.5)$ & & \\
\hline T3 & $16(23.2)$ & $27(40.9)$ & $28(35.4)$ & $6(26.1)$ & $61(36.3)$ & & \\
\hline $\mathrm{T} 4$ & $11(15.9)$ & $8(12.1)$ & $10(12.7)$ & $4(17.4)$ & $22(13.1)$ & & \\
\hline$N$ & & & & & & 0.550 & 0.542 \\
\hline No & $49(71)$ & $41(62.1)$ & $56(70.9)$ & $14(60.9)$ & $111(66.1)$ & & \\
\hline N1 & $20(29)$ & $25(37.9)$ & $23(29.1)$ & $9(39.1)$ & 57 (33.9) & & \\
\hline$M$ & & & & & & 0.720 & 0.558 \\
\hline M0 & $45(65.2)$ & $38(57.6)$ & $51(64.6)$ & $13(56.5)$ & $102(60.7)$ & & \\
\hline M1 & $24(34.8)$ & $28(42.4)$ & $28(35.4)$ & $10(43.5)$ & $66(39.3)$ & & \\
\hline High risk & $50(72.5)$ & $57(86.4)$ & $66(83.5)$ & $21(91.3)$ & $144(85.7)$ & 0.086 & 0.025 \\
\hline
\end{tabular}

Data are expressed as $n(\%)$ or mean \pm SD. The bold value indicated statistical significance. $\mathrm{PC}=$ prostate cancer; $\mathrm{BMI}=$ body mass index; PSA $=$ prostatespecific antigen. $P$ value ${ }^{\mathrm{a}}$ for comparison among ABO blood types; $P$ value ${ }^{\mathrm{b}}$ for comparison between non-O and $\mathrm{O}$ blood types.

TABLe 3: Univariate analysis for high-risk patients with PC.

\begin{tabular}{lccc}
\hline & \multicolumn{2}{c}{ Univariate model } & \multirow{2}{*}{ OR } \\
& 1.011 & $0.970-1.054$ & 0.608 \\
\hline Age & 1.615 & $0.804-3.247$ & 0.178 \\
BMI & 1.362 & $0.668-2.778$ & 0.396 \\
Hypertension & 0.941 & $0.383-2.310$ & 0.894 \\
Diabetes mellitus & 1.558 & $0.570-4.255$ & 0.387 \\
Coronary artery disease & 1.139 & $1.077-1.205$ & $<\mathbf{0 . 0 0 1}$ \\
PSA & 9.465 & $4.869-18.400$ & $<\mathbf{0 . 0 0 1}$ \\
Gleason score & 0.439 & $0.222-0.868$ & $\mathbf{0 . 0 1 8}$ \\
O (versus non-O) & 0.511 & $0.243-1.074$ & 0.077 \\
A (versus non-A) & 0.659 & $0.331-1.311$ & 0.235 \\
B (versus non-B) & 0.402 & $0.091-1.783$ & 0.230 \\
AB (versus non-AB) & 2.280 & $1.152-4.512$ & $\mathbf{0 . 0 1 8}$ \\
non-O (versus O) &
\end{tabular}

Univariate regression analyses are applied. The bold value indicated statistical significance. $\mathrm{PC}=$ prostate cancer; $\mathrm{BMI}=$ body mass index; PSA $=$ prostate-specific antigen .

gastric cancer in 1953 by Arid et al. [21], the relationship between the $\mathrm{ABO}$ blood group and the risk, incidence, and clinicopathologic characteristics of human tumors has been suspected. Previous studies have generally shown an increased risk of cancer, including pancreas, ovarian, and renal, for non-type $\mathrm{O}$ blood group compared to type $\mathrm{O}$ $[13,14,22]$. Wolpin et al. reported that people with non-O blood groups have an adjusted hazard ratio (HR) for pancreatic cancer of 1.44 (95\% confidence interval [CI] 1.14-1.82),
TABLE 4: Multivariate analysis to identify the independent correlation between non-O blood type and high risk of PC.

\begin{tabular}{|c|c|c|c|c|}
\hline \multirow{2}{*}{ Models } & \multirow{2}{*}{ Variables } & \multicolumn{2}{|c|}{ Multivariate model } & \multirow{2}{*}{$P$ value } \\
\hline & & OR & $95 \%$ CI & \\
\hline 1 & Non-O & 2.280 & $1.152-4.512$ & 0.018 \\
\hline 2 & Model $1+$ covariates & 2.443 & $1.215-4.914$ & 0.012 \\
\hline 3 & Model $2+$ PSA & 3.525 & $1.221-10.178$ & 0.020 \\
\hline 4 & $\begin{array}{c}\text { Model } 3+\text { Gleason } \\
\text { score }\end{array}$ & 33.066 & $\begin{array}{c}2.391- \\
457.323\end{array}$ & 0.009 \\
\hline
\end{tabular}

Multivariate regression stepwise models are shown. The bold value indicated statistical significance. The dependent variable was high-risk PC. Model 1 was unadjusted. Model 2 corrected for covariates including age, body mass index, hypertension, diabetes mellitus, and coronary artery disease. Model 3 additionally corrected for PSA based on Model 2; Model 4 additionally corrected for Gleason Score based on Model 3. PSA = prostate-specific antigen; $\mathrm{PC}=$ prostate cancer.

compared with people with blood group O [22]. Several plausible mechanisms, such as intercellular adhesion and membrane signaling, inflammation, and immune surveillance of malignant cells, have been proposed to explain this observed association between the $\mathrm{ABO}$ blood group and cancer risk [22]. Moreover, some studies have suggested a possible relationship between $\mathrm{ABO}$ blood group antigens and progression of human tumors [15, 23-27].

However, few studies on the relationship between $\mathrm{ABO}$ blood types and PC have been reported. We reviewed the literatures and found that Rummel and Ellsworth [12] had reported that there was no association between blood type and PC risk or survival, but whether loss of antigen 
expression increases with tumor progression or invasion is controversial. Besides, one recent study demonstrated that there is no association between $\mathrm{ABO}$ blood type and risk of aggressive PC [28]. Almost all the mentioned studies compared the PC patients with normal people and did not reveal the relationship between $\mathrm{ABO}$ blood types and risk of aggressiveness or invasion in patients with PC.

Our study divided PC patients into two groups: Lowmiddle-risk group and high-risk group, and then analyzed the association of $\mathrm{ABO}$ blood types and clinicopathological features in the two groups. Our study showed, by both univariate and multivariate analyses, blood type non-O were independently correlated with the presence of high-risk PC. Compared with patients with other ABO blood groups, patients with blood group $\mathrm{O}$ had significantly lower risk of invasion. Although, there were no significant differences on bone metastasis or positive pelvic lymph node between individuals with different $\mathrm{ABO}$ blood types, we can also see a trend that patients with blood group $\mathrm{O}$ had significantly lower risk of bone and lymph node metastasis, which was consistent with the main result of our study.

Although the study design is different, our findings are similar to those of previous studies [12] in other cancer fields including pancreatic, gastric, breast, colorectal, ovarian, and esophageal cancer, all of which revealed that blood group $\mathrm{O}$ decreased cancer risk compared with the non-O group. Moreover, our present study provided that in PC patients, non-O blood type was strongly and positively associated with high risk, which was independent of other confounders including the established PC risk factors such as PSA and Gleason score. Therefore, our data extended previous studies and provided new information with regard to the clinical application of $\mathrm{ABO}$ blood types.

Given the potential mechanisms of this correlation of $\mathrm{ABO}$ blood types and clinicopathological features remain uncertain and need further studies, we suggest PC patients with non-O blood type may have higher risk and should receive more attention in clinical practice. As for the treatment protocols, the percentage of radical prostatectomy in low-middle-risk group was significantly higher than that in the high-risk group because some patients with high risk especially with metastasis lost the opportunity of radical prostatectomy when diagnosis was confirmed.

There were several limitations in our study. Firstly, it was conducted at a single center. Secondly, this was an observational study and so still there could be residual confounding. Thirdly, we did not evaluate the prognostic value of $\mathrm{ABO}$ blood type in our population. Finally, we did not apply the new 2014 ISUP grading system to our study due to pathological report limitations. Further study is needed to examine the role of $\mathrm{ABO}$ blood type in predicting the clinical outcomes in a large sample size and long-term follow-up.

\section{Conclusions}

In conclusion, this study provides evidence of an association between the ABO blood group and clinicopathological features of prostate cancer: patients with blood group $\mathrm{O}$ had lower risk rate than patients with non-O blood groups. This association remained significant after adjustment for other known risk factors. Further basic research on tumor genetic or biological differences associated with the ABO blood group is needed in the future studies.

\section{Conflicts of Interest}

The authors declare that they have no conflicts of interests.

\section{Acknowledgments}

This work was supported by the Specialized Research Fund for the Doctoral Program of The Affiliated Hospital of Qingdao University (111520) awarded to Dr. Fang-Ming Wang, MD, PhD.

\section{References}

[1] J. Ferlay, E. Steliarova-Foucher, J. Lortet-Tieulent et al., "Cancer incidence and mortality patterns in Europe: estimates for 40 countries in 2012," European Journal of Cancer, vol. 49, no. 6, pp. 1374-1403, 2013.

[2] J. Ferlay, I. Soerjomataram, R. Dikshit et al., "Cancer incidence and mortality worldwide: sources, methods and major patterns in GLOBOCAN 2012," International Journal of Cancer, vol. 136, no. 5, pp. E359-E386, 2015.

[3] Y. Zhu, H. K. Wang, Y. Y. Qu, and D. W. Ye, "Prostate cancer in East Asia: evolving trend over the last decade," Asian Journal of Andrology, vol. 17, no. 1, pp. 48-57, 2015.

[4] M. Franchini, E. J. Favaloro, G. Targher, and G. Lippi, “ABO blood group, hypercoagulability, and cardiovascular and cancer risk," Critical Reviews in Clinical Laboratory Sciences, vol. 49, pp. 137-139, 2012.

[5] J. P. Reilly, N. J. Meyer, M. G. S. Shashaty et al., "ABO blood type A is associated with increased risk of ARDS in whites following both major trauma and severe sepsis," Chest, vol. 145, pp. 753-761, 2014.

[6] M. He, B. Wolpin, K. Rexrode et al., "ABO blood group and risk of coronary heart disease in two prospective cohort studies," Arteriosclerosis, Thrombosis, and Vascular Biology, vol. 32, no. 9, pp. 2314-2320, 2012.

[7] F. Dentali, A. P. Sironi, W. Ageno et al., "Non-O blood type is the commonest genetic risk factor for VTE: results from a meta-analysis of the literature," Seminars in Thrombosis and Hemostasis, vol. 38, no. 5, pp. 535-548, 2012.

[8] A. K. Panda, S. K. Panda, A. N. Sahu, R. Tripathy, B. Ravindran, and B. K. Das, "Association of $\mathrm{ABO}$ blood group with severe falciparum malaria in adults: case control study and meta-analysis," Malaria Journal, vol. 10, p. 309, 2011.

[9] F. Dentali, A. P. Sironi, W. Ageno et al., "Relationship between $\mathrm{ABO}$ blood group and hemorrhage: a systematic literature review and meta-analysis," Seminars in Thrombosis and Hemostasis, vol. 39, no. 1, pp. 72-82, 2013.

[10] P. N. Alpoim, M. de Barros Pinheiro, D. R. Junqueira et al., "Preeclampsia and ABO blood groups: a systematic review and meta-analysis," Molecular Biology Reports, vol. 40, no. 3, pp. 2253-2261, 2013. 
[11] B. M. Wolpin, P. Kraft, M. Gross et al., "Pancreatic cancer risk and $\mathrm{ABO}$ blood group alleles: results from the pancreatic cancer cohort consortium," Cancer Research, vol. 70, no. 3, pp. 1015-1023, 2010.

[12] S. K. Rummel and R. E. Ellsworth, "The role of the histoblood ABO group in cancer," Future Science OA, vol. 2, no. 2, article FSO107, 2016.

[13] M. A. Gates, B. M. Wolpin, D. W. Cramer, S. E. Hankinson, and S. S. Tworoger, "ABO blood group and incidence of epithelial ovarian cancer," International Journal of Cancer, vol. 128, no. 2, pp. 482-486, 2011.

[14] H. K. Joh, E. Cho, and T. K. Choueiri, "ABO blood group and risk of renal cell cancer," Cancer Epidemiology, vol. 36, no. 6, pp. 528-532, 2012.

[15] J. Xie, A. A. Qureshi, Y. Li, and J. Han, "ABO blood group and incidence of skin cancer," PLoS One, vol. 5, no. 8, article e11972, 2010.

[16] J. I. Epstein, W. C. Allsbrook Jr., M. B. Amin, L. L. Egevad, and ISUP Grading Committee, "The 2005 International Society of Urological Pathology (ISUP) consensus conference on Gleason grading of prostatic carcinoma," The American Journal of Surgical Pathology, vol. 29, pp. 1228$1242,2005$.

[17] B. Kilgore and J. H. Liu, "Iso-agglutination test of Chinese bloods for transfusion compatibility," Chinese Medical Journal, vol. 32, p. 21, 1918.

[18] J. A. Strauchen, S. M. Bergman, and T. A. Hanson, "Expression of A and B tissue isoantigens in benign and malignant lesions of the breast," Cancer, vol. 45, pp. 2149$2155,1980$.

[19] M. H. Schuessler, S. Pintado, S. Welt et al., "Blood group and blood-group-related antigens in normal pancreas and pancreas cancer: enhanced expression of precursor type 1, Tn and sialyl-Tn in pancreas cancer," International Journal of Cancer, vol. 47, pp. 180-187, 1991.

[20] M. E. Reid and N. Mohandas, "Red blood cell blood group antigens: structure and function," Seminars in Hematology, vol. 41, pp. 93-117, 2004.

[21] I. Arid, H. H. Bentall, and J. A. Roberts, "A relationship between cancer of stomach and the ABO blood groups," British Medical Journal, vol. 1, pp. 799-801, 1953.

[22] B. M. Wolpin, A. T. Chan, P. Hartge et al., "ABO blood group and the risk of pancreatic cancer," Journal of the National Cancer Institute, vol. 101, pp. 424-431, 2009.

[23] Y. Gong, Y. S. Yang, X. M. Zhang et al., "ABO blood type, diabetes and risk of gastrointestinal cancer in northern China," World Journal of Gastroenterology, vol. 18, pp. 563-569, 2012.

[24] M. A. Gates, M. Xu, W. Y. Chen, P. Kraft, S. E. Hankinson, and B. M. Wolpin, "ABO blood group and breast cancer incidence and survival," International Journal of Cancer, vol. 130, pp. 2129-2137, 2012.

[25] D. S. Wang, D. L. Chen, C. Ren et al., "ABO blood group, hepatitis B viral infection and risk of pancreatic cancer," International Journal of Cancer, vol. 131, pp. 461-468, 2012.

[26] L. Sheng, X. Sun, L. Zhang, and D. Su, “ABO blood group and nasopharyngeal carcinoma risk in a population of Southeast China," International Journal of Cancer, vol. 133, pp. 893$897,2013$.
[27] F. Tavasolian, E. Abdollahi, M. Vakili, and A. Amini, "Relationship between ABO blood group and acute lymphoblastic leukemia," Iranian Journal of Pediatric Hematology and Oncology, vol. 4, pp. 1-4, 2014.

[28] S. C. Markt, I. M. Shui, R. H. Unger et al., "ABO blood group alleles and prostate cancer risk: results from the breast and prostate cancer cohort consortium (BPC3)," Prostate, vol. 75, no. 15, pp. 1677-1681, 2015. 


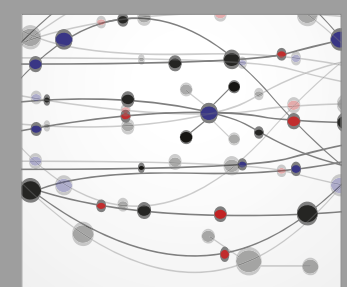

The Scientific World Journal
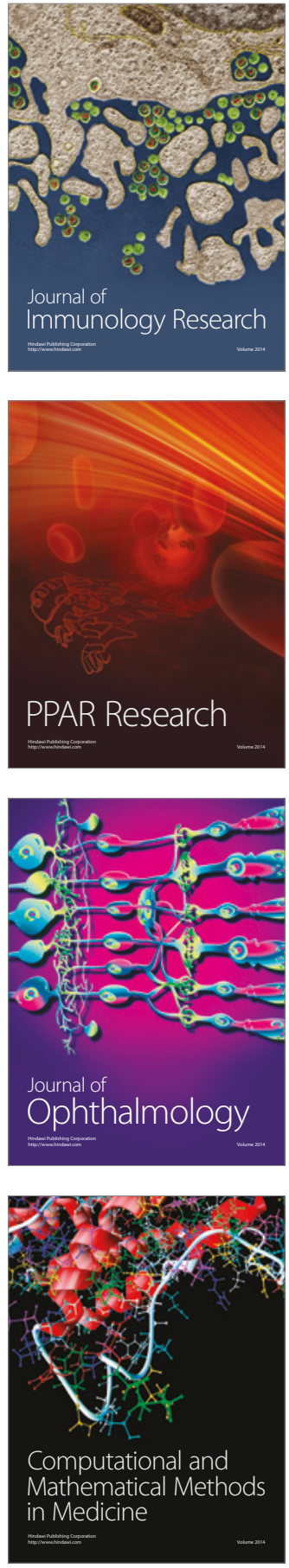

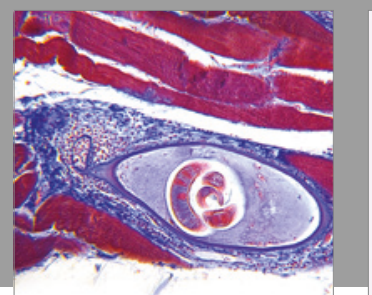

Gastroenterology Research and Practice
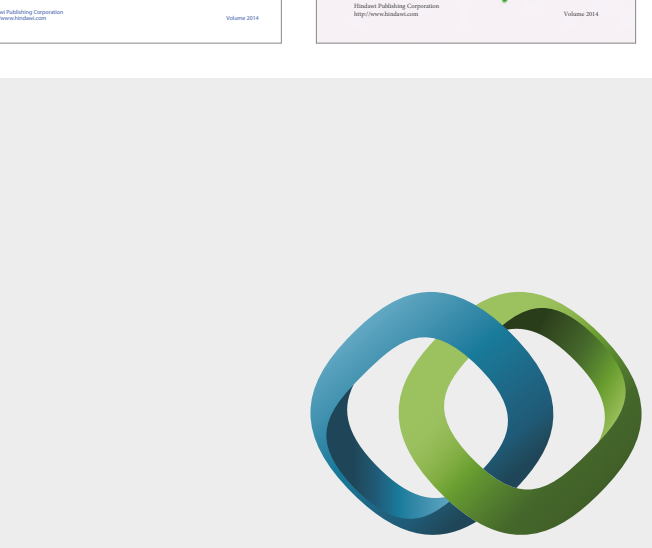

\section{Hindawi}

Submit your manuscripts at

https://www.hindawi.com
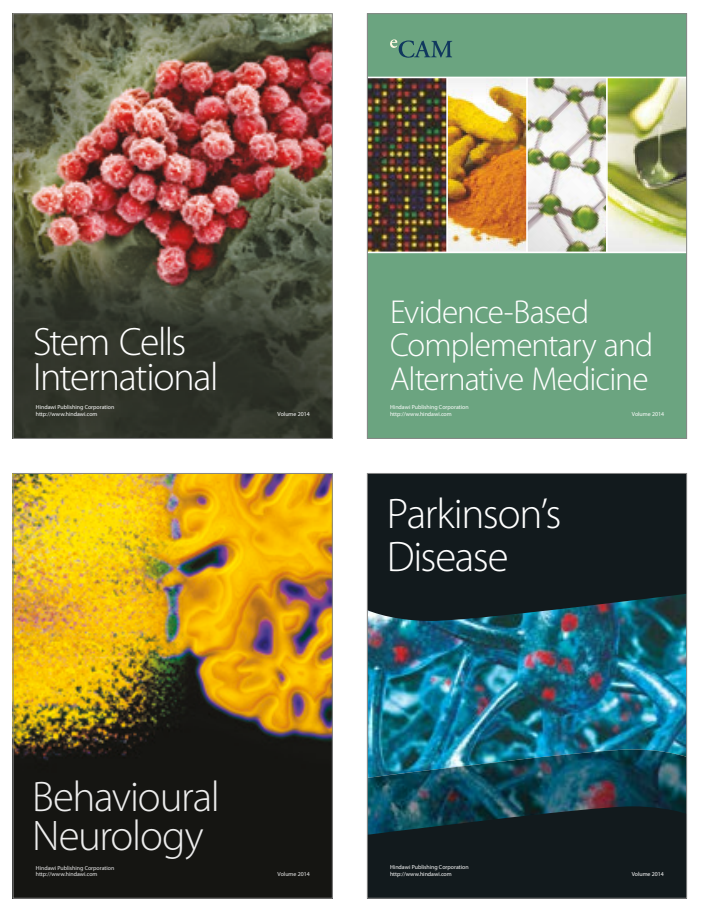
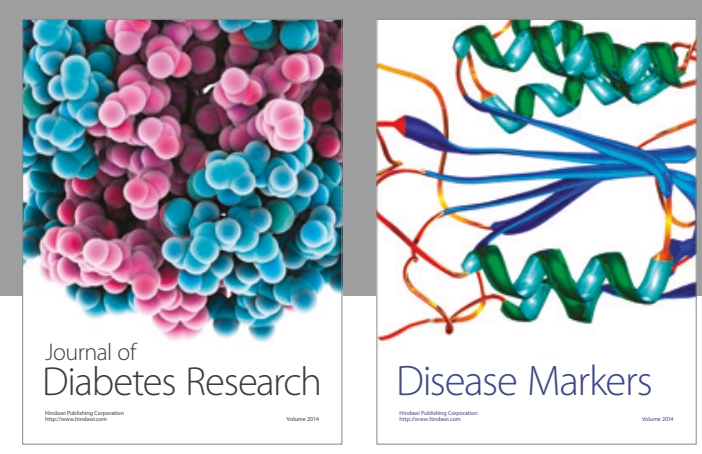

Disease Markers
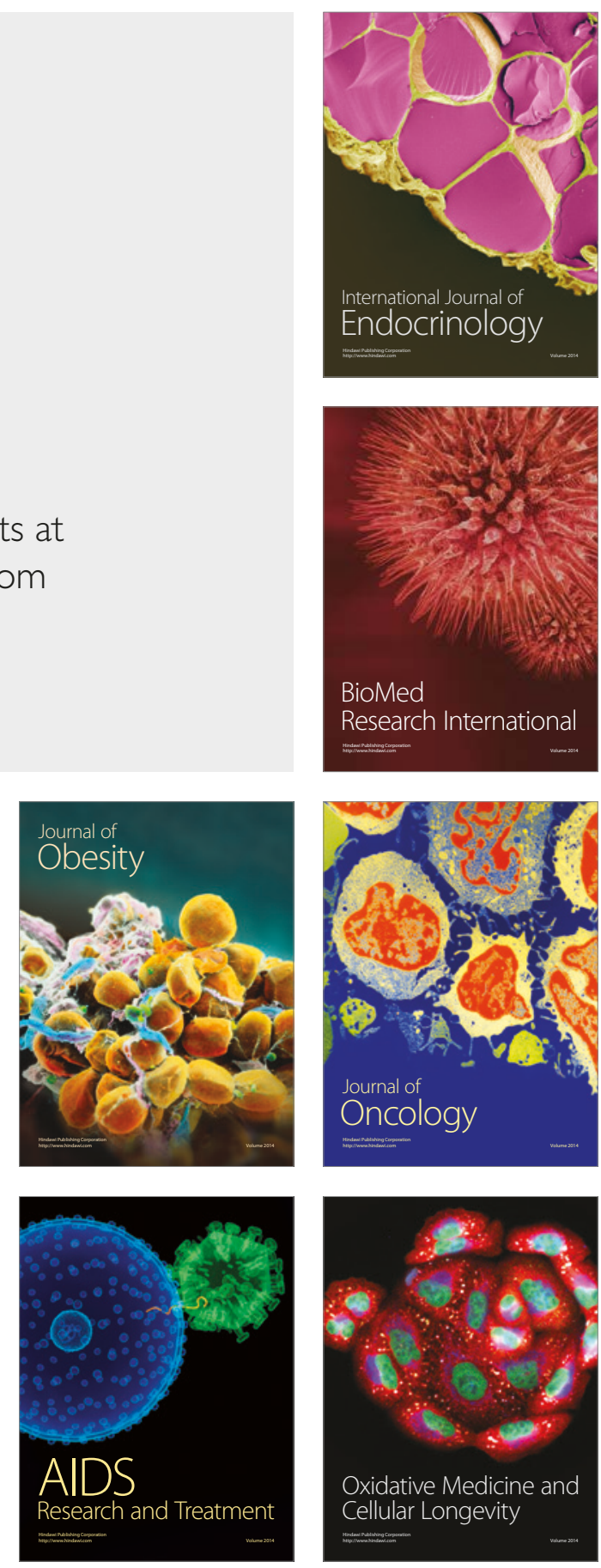